\title{
EI Niño events, precipitation patterns, and rodent outbreaks are statistically associated in semiarid Chile
}

\author{
Mauricio Lima, Pablo A. Marquet and Fabian M. Jaksic
}

Lima, M., Marquet, P. A. and Jaksic, F. M. 1999. El Niño events, precipitation patterns, and rodent outbreaks are statistically associated in semiarid Chile. Ecography 22: 213-218.

\begin{abstract}
In the last two decades, several researchers have noted rodent population outbreaks in semiarid South America, in association with unusually high precipitation that seemingly concurs with El Niño events. To date, no studies have been conducted to determine the statistical relationships between ENSO (El Niño Southern Oscillation) events, increased precipitation, and rodent irruptions. Here we show that: 1) there is a statistical association between ENSO events and increased precipitation in the semiarid region of northern Chile; 2) the occurrence of rodent outbreaks in that region is statistically related with the precipitation levels of the same year; 3 ) the multi-annual patterns of the total annual precipitation levels and population abundance of those rodents during the summer are positively associated. The putative chain of effects seems to start with unusually high rainfall brought by ENSO to semiarid environments, which thus respond with increased primary productivity (herbage and seeds), which then fuels the rodent outbreaks.
\end{abstract}

M. Lima (mlima@abello.dic.uchile.cl),Dept de Ciencias Ecológicas, Univ. de Chile, Casilla 653, Santiago, Chile. - P. A. Marquet, and F. M. Jaksic, Dept de Ecologia. Pontificia Univ. Católica de Chile, Casilla 114-D, Santiago, Chile.

Although rodent populations in the Neotropical region have been much less studied than those in the Holarctic region (Hansson and Henttonen 1988, Stenseth and Ims 1993, Norrdahl and Korpimäki 1995), there is circumstantial evidence that the former undergo marked population fluctuations (O'Connell 1986). Their population peaks often reach so high that they are considered agricultural pests that cause heavy economic losses in most of the Neotropics (Rodríguez 1993). Unfortunately, much of the information is anecdotal, or at best short-spanned, and thus there are no adequate databases that may enable a better understanding of the mechanisms that underlie such population fluctuations. Still, some patterns are evident. O'Connell (1986), in her review of rodent population variability patterns in the Neotropics, noted that it was cricetid rodents which displayed the most dramatic peaks, in particular those from western South America. Indeed, historical records have long existed about rodent outbreaks in that re- gion, either in association with masting shrubs or unusual precipitation. As far back as 1960's, those outbreaks or irruptions were considered to be similar or equivalent to those displayed by microtines in the Northern Hemisphere (Hershkovitz 1962).

A case in point is Chile, where since 1780 there have been anecdotal records of rodent outbreaks around the southern town of Valdivia, in association with masting bamboo Chusquea spp. (Philippi 1879, Hershkovitz 1962, Murúa et al. 1986, 1996). Better documented yet, have been the rather more frequent rodent irruptions in semiarid zones of southern Peru and northern Chile, in apparently close association with periods of high precipitation (Pearson 1975, Péfaur et al. 1979, Fuentes and Campusano 1985, Meserve and Le Boulengé 1987, Meserve et al. 1995). In this latter case, the species involved are essentially three cricetids: Phyllotis darwini $(50 \mathrm{~g})$, Akodon olivaceus (27 g), and Oligoryzomys longicaudatus $(28 \mathrm{~g})$.

Accepted 4 September 1998

Copyright (C) ECOGRAPHY 1999

ISSN 0906-7590

Printed in Ireland - all rights reserved 
In particular, the herbivore-granivore leaf earedmouse Phyllotis darwini has been reported for experiencing the most dramatic population outbreaks, and it has not gone unnoticed (Péfaur et al. 1979, Jiménez et al. 1992, Jaksic et al. 1993, 1996, 1997, Meserve et al. 1995) that they seemingly concur with ENSO events (El Niño Southern Oscillation). The putative chain of effects would be increased primary productivity (herbage and seeds) associated with unusually high rainfall brought by ENSO to semiarid environments (Armesto et al. 1993, Gutiérrez et al. 1993, Jaksic et al. 1997). This assumed causal relationship has led some researchers to consider some rodent populations as nonregulated and driven by extrinsic climatic factors (Meserve and Le Boulengé 1987, Meserve et al. 1995). By contrast, we have determined strong delayed density-dependent factors operating at demographic (Lima and Jaksic 1998a) and population dynamic (Lima and Jaksic 1998b, 1999) levels in this species. In sum, to date no studies have been conducted to determine the statistical relationships between ENSO events, increased precipitation, and rodent fluctuations. This is what we do in our paper.

First, we statistically analyse the relationships between ENSO events and inter-annual variability of precipitation, as well as the relationship of both phenomena with reliable historical records of rodent population irruptions in semiarid Chile. Secondly, on the basis of a long-term database on a metapopulation of the rodent Phyllotis darwini (Lima et al. 1996. TorresContreras et al. 1997) in a specific locality of northern Chile, we analyse the relationship between population abundance and precipitation, at a multi-annual temporal scale.

\section{Material and methods}

\section{Meteorological and climatological data}

One of the indices used to estimate the occurrence and intensity of the El Niño Southern Oscillation (ENSO) is the Southern Oscillation Index (SOI), that compares meteorological conditions in two tropical areas of the Pacific Ocean (Allen et al. 1996). The SOI is calculated by subtracting from the monthly-standardised atmospheric pressure measured in Tahiti that recorded in Darwin, Australia. The SOI is reported as a 5-month moving average. Periods characterised by low index values (negative) correspond to ENSO events wherein warm tropical waters intrude into the western coasts of the Americas - whereas those periods characterised by high index values (positive) correspond to events denominated La Niña - when the cold Humboldt and California currents bathe the Americas' coastlines. For our analyses we used the SOI index values obtained from 1943 to 1997 . Values of this index over the last century are accessible through the Internet web site of the National Oceanographic and Atmospheric Administration (NOAA) of the USA.

Monthly precipitation data were obtained from the climatological stations of Hurtado $\left(30^{\circ} 17^{\prime} \mathrm{S} ; 70^{\circ} 41^{\prime} \mathrm{W}\right.$; 1200 m elevation; period 1943-1997), Pichasca $\left(30^{\circ} 23^{\prime} \mathrm{S} ; 70^{\circ} 52^{\prime} \mathrm{W} ; 750 \mathrm{~m}\right.$ elevation; period 1946-1997) - both located in the Limarí River basin - and Illapel (31 ${ }^{\circ} 38^{\prime} \mathrm{S} ; 71^{\circ} 10^{\prime} \mathrm{W} ; 290 \mathrm{~m}$ elevation; period 1987-1997)

located in the Choapa River basin. Data from the former two locations were deemed as adequate representations of climatological conditions in northern Chile, largely because they provided the longest time series. Data from the third one - although a short time series - were deemed as representative of local conditions experienced in our primary study site at Aucó, located approximately $18 \mathrm{~km}$ away of the Illapel station.

\section{Rodent irruptions at regional and local levels}

At the regional level, we determined the occurrence and frequency of rodent outbreaks in northern Chile by means of historical records published in local newspapers from several towns and cities in the region, particularly those in the basin of the rivers Elqui and Limarí. Presence and absence of rodent irruptions was tracked from 1943 to 1980 (see Fuentes and Campusano 1985, for details).

At the local level, we applied capture-mark-recapture (CMR) procedures from 1987 to 1997 to four mammal subpopulations (two in equatorial-exposed, xeric habitats, and two in polar-exposed, mesic habitats) in two creeks of the Reserva Nacional Las Chinchillas, at Aucó $\left(31^{\circ} 30^{\prime} \mathrm{S} ; 71^{\circ} 08^{\prime} \mathrm{W}\right)$. Live-trapping was conducted in El Cobre and El Grillo creeks (separated by $2 \mathrm{~km}$ in straight line) from October 1987 to December 1991 in El Cobre and from November 1987 to January 1992 in El Grillo, every other month, alternating between one creek and the other (that is, six times a year in each creek). From July 1992 to October 1997, live-trapping was relaxed to every three months (that is, in January, April, July and October) and effected only in the two subpopulations of El Cobre creek.

Each grid had $7 \times 7$ live-trapping stations spaced 15 $\mathrm{m}$ and equipped with a single Sherman-type trap, covering an area of $105 \times 105 \mathrm{~m}$ (which includes a peripheral boundary strip of $7.5 \mathrm{~m}$ ), thus representing 49 traps in 1.1 ha per grid. In either creek, both xeric and mesic grids were activated simultaneously during five consecutive nights. All traps remained permanently in the field, and were closed when not in use. Rolled oats was the bait, and all activated traps were checked every morning. Each mammal individual captured was marked with a metallic ear tag, and the species, sex, body mass, and reproductive status was recorded. An 
abundance index was estimated as the minimum number of individuals known alive (Krebs 1989). The relative abundances of $P$. darwini catches are higher during the breeding seasons (spring and summer; Meserve and Le Boulengé 1987, Jiménez et al. 1992) and resulted in pronounced fluctuations. The overall lower variations during autumn and winter result in less pronounced variations, which presumably are more sensitive to random sampling variations. The less consistent variations of the autumn and winter did not permit consistent analyses of these data. Hence, only summer counts from El Cobre creek (eleven years) have been considered for the analysis.

\section{Statistical analyses}

With the aim of assessing any statistical relationships between El Niño events, precipitation records, and rodent outbreaks, we used tools for the analysis of time series. Total annual precipitation records obtained in the Hurtado and Pichasca climatological stations were analysed with reference to the SOI summed up yearly, by means of the Cross Correlation Function (CCF) (Chatfield 1989).

To determine the relationship (if any) between precipitation and rodent irruptions, we applied a logistic regression analysis (Trexler and Travis 1993) between the occurrence of rodent outbreaks (presence-absence) and yearly cumulative precipitation records from Hurtado and Pichasca, separately. Precipitation was logtransformed in order to normalise its distribution. We evaluated the contribution of each parameter (logtransformed precipitation) using a $\log$ likelihood $\chi^{2}$ ratio test, which compares the log likelihood of a given model to a model with its only parameter being a constant (Trexler and Travis 1993).

The relationship between total annual precipitation records and the summer population abundance of the rodent Phyllotis darwini in Aucó was analysed for the years 1987-1997. With the aim of determining any statistical relationship between rodent abundance and precipitation, we applied linear regression between total annual precipitation and summer population abundance of Phyllotis darwini during the summer season of every year.

\section{Results}

\section{El Niño events and precipitation patterns}

Low values of the SOI (i.e., El Niño events) were associated with increased precipitation in the two Chilean localities with long-term data, while La Niña years (high values of SOI) were associated to below-average precipitation levels (Fig. 1). The Cross Correla- tion Function yielded a significant negative relationship at interval 0 between the Southern Oscillation Index and the yearly cumulative precipitation in the two localities considered (Fig. 2). This indicates that at least statistically there is evidence that El Niño events bring associated increased precipitation in the semiarid region of Chile. However, the rather low (but significant) coefficients between ENSO and precipitation indicate a not very strong relationship.

\section{Precipitation patterns and rodent outbreaks}

According to Fuentes and Campusano (1985) there is historical evidence for eight rodent irruptions in northern Chile between 1940 and 1980. Unfortunately, there are no records of the magnitude of those outbreaks or of the rodent species involved. Nevertheless, the logistic regression model was significant when we considered the climatological data from Hurtado $\left(\chi^{2}=19.29\right.$; $\mathrm{DF}=1 ; \mathrm{p}<0.0001 ;$ Fig. $3 \mathrm{a})$, and when using data from Pichasca $\left(\chi^{2}=24.74 ; \mathrm{DF}=1 ; \mathrm{p}<0.0001\right.$; Fig. $\left.3 b\right)$. In both cases the regression model was significant, which points out the close relationship between precipitation and probability of occurrence of rodent irruptions.

\section{Precipitation patterns and rodent abundances}

The precipitation pattern in northern Chile (as exemplified by the Illapel climatological station) is highly seasonal, with rainfall concentrated during winter months and a virtual absence during the summer (Fig. 4). The summer population abundance of Phyllotis darwini shows a clear relationship with the total annual precipitation pattern (Fig. 5). When comparing the total annual precipitation levels and the respective pop-

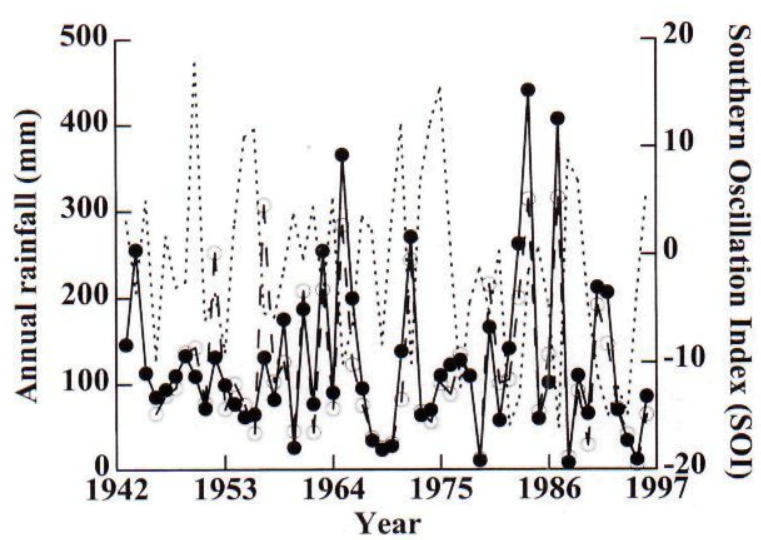

Fig. 1. Fluctuations of the annual cumulative precipitation levels at two climatological stations in semiarid Chile: Hurtado (closed dots and solid line), and Pichasca (open dots and broken line), and the Southern Oscillation Index (SOI; dotted line). 

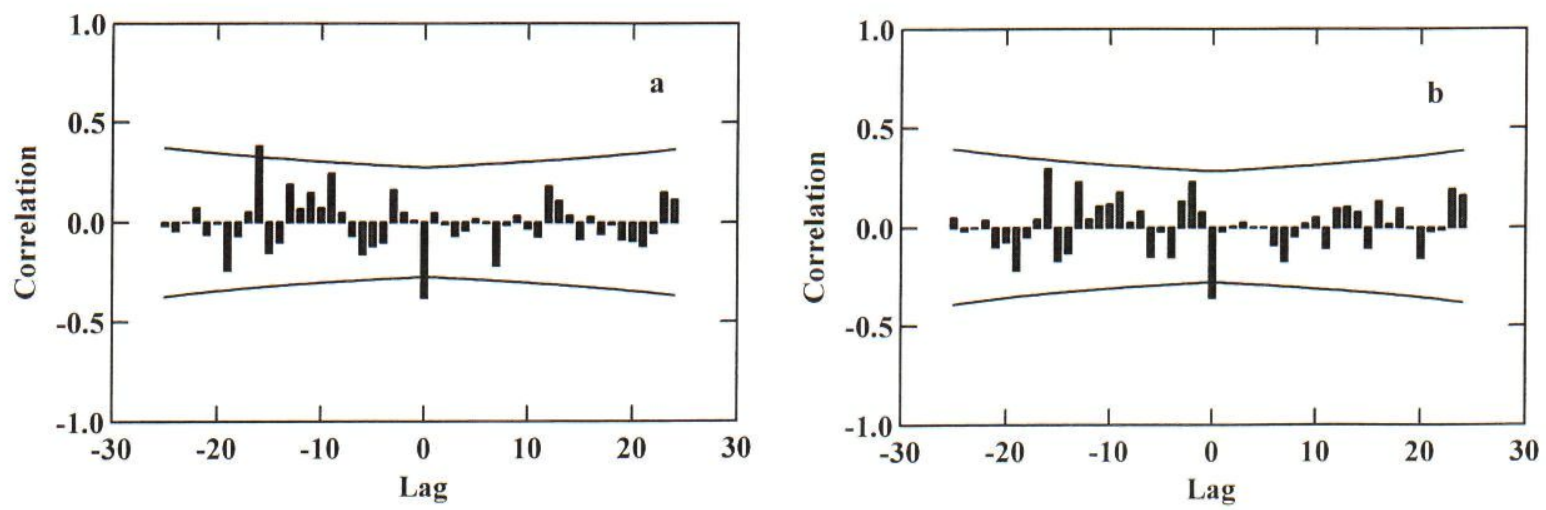

Fig. 2. Cross Correlation Function between the annual cumulative precipitation levels at two climatological stations in semiarid Chile. a) Hurtado station. b) Pichasca station. The horizontal lines encompass the $95 \%$ confidence Bartlett band $\left( \pm 2 / \mathrm{T}^{1 / 2}\right.$; where $\mathrm{T}$ is the length of the time series). The significant negative coefficients at lag $=0$ indicate the relationship between ENSO events and increased annual precipitation.
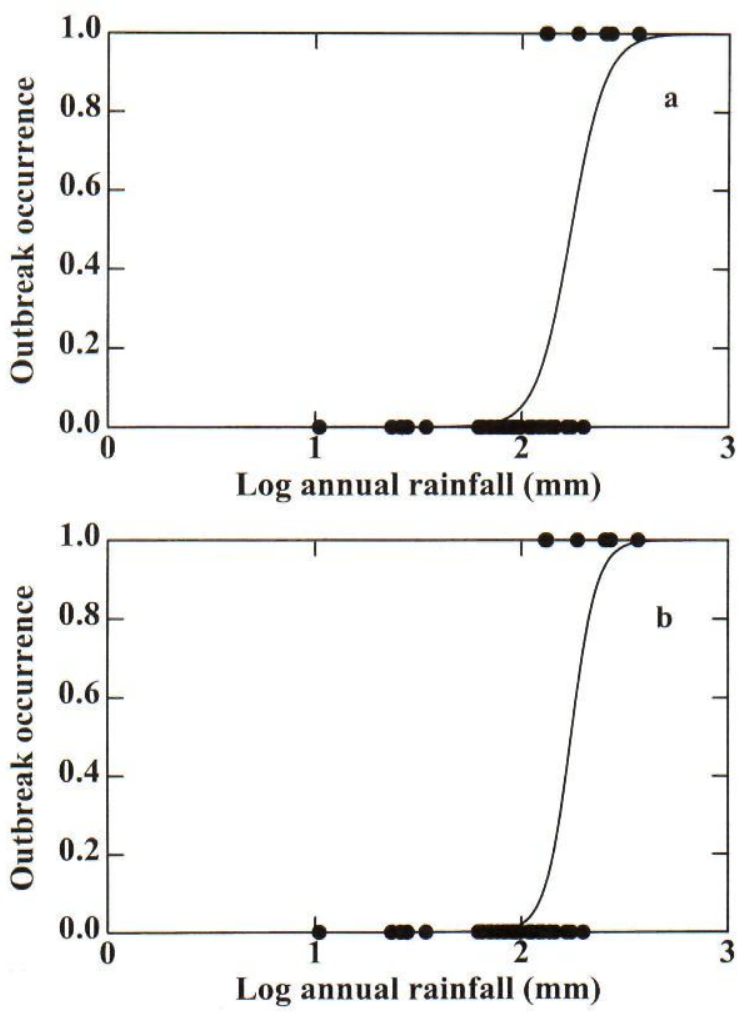

Fig. 3. Logistic regression of the occurrence of rodent outbreaks in northern Chile (taken from Fuentes and Campusano 1985) in years between 1943 and 1980 and the total annual rainfall in a) Hurtado station (logistic regression model

$y=\frac{\exp [-27.19+(12.15 * x]}{\{1+\exp [-27.19+(12.15) * x]\}}$

and b) Pichasca station logistic regression model

$y=\frac{\exp [-36.28+(16.24 * x]}{\{1+\exp [-36.28+(16.24) * x]\}}$. ulation abundances of Phyllotis darwini during the summer, there is a significantly positive relationship between these variables in both habitat types (xeric: $\mathrm{R}^{2}=0.73 ; \mathrm{DF}=1,9 ; \mathrm{F}=23.88 ; \mathrm{p}=0.0009 ;$ mesic: $\left.\mathrm{R}^{2}=0.66 ; \mathrm{DF}=1,9 ; \mathrm{F}=16.99 ; \mathrm{p}=0.003\right)$.

\section{Discussion}

We have shown that: 1) there is a statistical association between El Niño events and increased precipitation in the semiarid region of northern Chile; 2) the occurrence of rodent outbreaks in that region is statistically related with the precipitation levels of the same year; 3) the multi-annual patterns of total annual precipitation levels and population abundance of Phyllotis darwini during the summer are positively associated.

The rodent Phyllotis darwini exhibited a seasonal dynamics, with increased population size toward spring and summer (Meserve and Le Boulengé 1987, Jiménez et al. 1992). Therefore, we believe that there are reasonably solid statistical links that imply some form of causality from El Niño events through precipitation patterns to rodent irruptions. We speculate on this causality below.

Because water is a limiting resource in semiarid regions, it does not come as a surprise that increased precipitation brings about increased primary production in the form of both herbage and seeds (Gutiérrez et al. 1993). In turn, because precipitation is concentrated during winter, both reproduction and recruitment of local rodents occur during the subsequent spring and summer months (Meserve and Le Boulengé 1987), a time when rodents may use the increased primary production that results from plant growth and reproduction (Armesto et al. 1993). This scenario was proposed by Jaksic et al. (1997) for the processes linking precipi- 


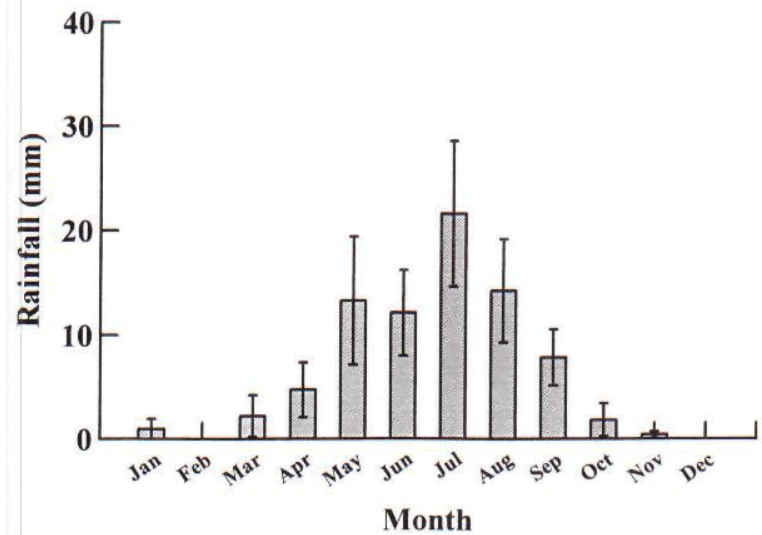

Fig. 4. Mean monthly rainfall in the locality of Illapel for the period 1987-1997 $(\mathrm{n}=11)$, indicating the strong seasonal pattern of the precipitation.

tation and outbreaks in northern Chile, but it has also been invoked as an explanation for rodent irruptions in other semiarid regions, such as those of Mus musculus in south-eastern Australia (Saunders and Giles 1977, Mutze et al. 1990), and of Mastomys spp. in central Africa (Leirs et al. 1996).

As shown for Phyllotis darwini in our study site, the abundance of this species track 5 closely precipitation levels. Therefore, a large population increase in face of unusually high precipitation is not unexpected. More interesting is the fact that Phyllotis darwini outbreaks are so quickly triggered, given that they shoot up within the same year of high precipitation (Jiménez et al. 1992, Meserve et al. 1995). With regard to this same species,

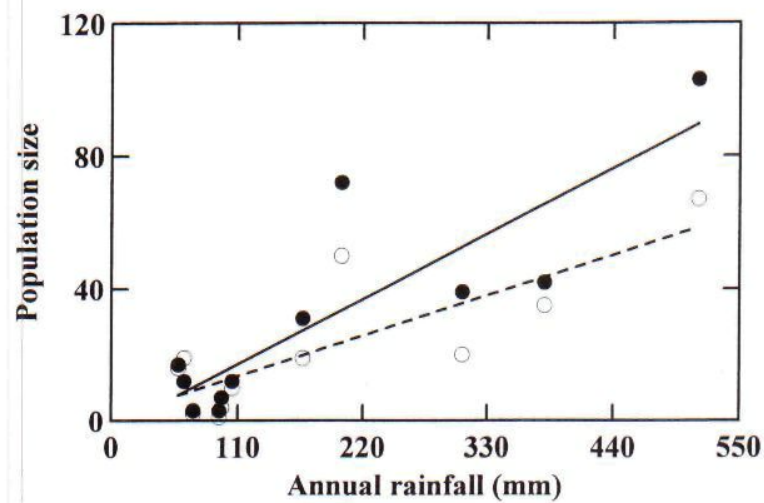

Fig. 5. Linear regression between the summer population size (minimum number of individuals alive in a study plot of 1.1 ha) of Phyllotis darwini in the locality of Auco and the total annual rainfall in the locality of Illapel for the period 1987$1997(\mathrm{n}=11)$. Closed dots and solid line are for the xeric subpopulation $\left(\mathrm{R}^{2}=0.73 ; \mathrm{DF}=1,9 ; \mathrm{F}=23.88 ; \mathrm{p}=0.0009\right)$ and open dots and broken line for the mesic subpopulation $\left(\mathrm{R}^{2}=0.66 ; \mathrm{DF}=1,9 ; \mathrm{F}=16.99 ; \mathrm{p}=0.003\right)$. but in southern Peru, Pearson (1975) had concluded that at least two years with higher than average precipitation were needed to trigger an outbreak. We tested this hypothesis with the long-term climatological data from Hurtado and Pichasca by means of a step-by-step logistic regression analysis, incorporating the cumulative precipitation fallen the year before to the eight rodent irruptions analysed. In none of the cases did we find a significant relationship, which reinforces our conclusion that it is the precipitation fallen the same year which triggers rodent population outbreaks.

In this study we have shown a close relationship between rodent irruptions and precipitation levels. Consequently, this result may be construed as supporting the hypothesis that density-dependent factors do not affect these population systems and that only densityindependent factors drive them (Meserve and Le Boulengé 1987, Meserve et al. 1995). This hypothesis is the classic "climatic control theory" (Bodenheimer 1938, Andrewartha and Birch 1954), applied to the strong sign of precipitation influencing population fluctuations of rodents in semiarid Chile. However, we have detected delayed density-dependent effects operating at demographic (Lima and Jaksic 1998a) and population dynamic (Lima and Jaksic 1998b, 1999) levels in $P$. darwini. These results strongly suggest that population fluctuations of this rodent species are driven by densitydependent factors and rainfall in combination.

In sum, we have determined some statistical relationships between environmental factors, rodent outbreaks, and population dynamics of rodent species in semiarid Chile. Nevertheless, to disentangle the final causes of these population irruptions, we should be able to connect specific demographic processes with population dynamic patterns. In this vein, we are currently studying the temporal structure and the role of densitydependent and density-independent factors on the basic demographic processes (survival, reproduction, and recruitment) of the species involved in the outbreaks.

Acknowledgements - M. Lima acknowledges a fellowship from the Vicerrectoría Académica of P. Univ. Católica de Chile for supporting his graduate studies. This research was funded by Fondo Nacional de Ciencia y Tecnología grants FONDECYT 296-0034 to ML, 195-1036 to PM, and 196-0319 to FMJ. FMJ acknowledges the support of the Mellon Foundations and of the Presidential Chair in Science.

\section{References}

Allen, R., Lindesay, J. and Parker, D. 1996. El Niño Southern Oscillation and Climatic Variability. - CSIRO, Collingwood, Australia

Andrewartha, H. G. and Birch, L. C. 1954. The distribution and abundance of animals. - Univ. Chicago Press.

Armesto, J. A., Vidiella, P. and Gutiérrez, J. R. 1993. Plant communities of the fog-free coastal desert of Chile: plant strategies in a fluctuating environment. - Rev. Chil. Hist. Nat. 66: 271-282. 
Bodenheimer, F. S. 1938. Problems of animal ecology. Oxford Univ. Press.

Chatfield, C. 1989. The analysis of time series. - Chapman and Hall.

Fuentes, E. R. and Campusano, C. 1985. Pest outbreaks and rainfall in the semi-arid region of Chile. - J. Arid Environ. 8: $67-72$.

Gutiérrez, J. R. et al. 1993. Structure and dynamics of vegetation in a Chilean arid thorn scrub community. - Acta Oecol. 14: 271-285.

Hansson, L. and Henttonen, H. 1988. Rodent dynamics as a community process. - Trends Ecol. Evol. 3: 195-200.

Hershkovitz, P. 1962. Evolution of Neotropical cricetine rodents (Muridae), with special reference to the Phyllotine group. - Fieldiana Zool. 46: 1-524.

Jaksic, F. M., Feinsinger, P. and Jiménez, J. E. 1993. A long-term study on the dynamics of guild structure among predatory vertebrates at a semi-arid Neotropical site. Oikos 67: 87-96.

Jaksic, F. M., Feinsinger, P. and Jiménez, J. E. 1996. Ecological redundancy and long-term dynamics of vertebrate predators in semiarid Chile. - Conserv. Biol. 10: 252-262.

Jaksic, F. M. et al. 1997. A long-term study of vertebrate predator responses to an El Niño (ENSO) disturbance in western South America. - Oikos 78: 341-354.

Jiménez, J. E., Feinsinger, P. and Jaksic, F. M. 1992. Spatiotemporal patterns of an irruption and decline of small mammals in northcentral Chile. - J. Mammal. 73: 356364.

Krebs, C. J. 1989. Ecological methodology. - Harper and Row.

Leirs, H. et al. 1996. Forecasting rodent outbreaks in Africa: an ecological basis for Mastomys control in Tanzania. - J. Appl. Ecol. 33: 937-943.

Lima, M. and Jaksic, F. M. 1998a. Delayed density-dependent and rainfall effects on reproductive parameters of an irruptive rodent in semarid Chile. - Acta Theriol. 43: 225-234.

Lima, M. and Jaksic, F. M. 1998b. Population variability among three small mammal species in the semiarid Neotropics: the role of density-dependent and density-independent factors. - Ecography 21: 175-180.

Lima, M. and Jaksic, F. M. 1999. Population dynamics of three Neotropical small mammals: time series models and the role of delayed density-dependence in population irruptions. - Aust. J. Ecol. 24: in press.

Lima, M., Marquet, P. A. and Jaksic., F. M. 1996. Extinction and colonization processes in subpopulations of five
Neotropical small mammal species. - Oecologia 107: 197203.

Meserve, P. L. and Le Boulengé, E. 1987. Population dynamics and ecology of small mammals in the northern Chilean semiarid region. - Fieldiana Zool. New ser. 39: 413-431.

Meserve, P. L. et al. 1995. Heterogeneous responses of small mammals to an El Niño southern oscillation event in northcentral semiarid Chile and the importance of the ecological scale. - J. Mammal. 76: 580-595.

Murúa, R., González, L. A. and Meserve, P. L. 1986. Population ecology of Oryzomys longicaudatus philippii (Rodentia: Cricetidae) in southern Chile. - J. Anim. Ecol. 55: 53-78.

Murúa, P. L., González, L. A. and Jofré, C. 1996. Efectos del florecimiento del arbusto Chusquea quila Kunth (Poaceae) sobre la demografía de poblaciones de roedores de los bosques templados fríos del sur chileno. - Bol. Soc. Biol. Concep. 67: $37-42$.

Mutze, G. J., Veitch, L. G. and Miller, R. B. 1990. Mouse plagues in south Australian cereal-growing areas. 2. An empirical model for prediction of plagues. - Aust. Wildl. Res. 17: 313-324.

Norrdahl, K. and Korpimäki, E. 1995. Effects of predator removal on vertebrate prey populations: birds of prey and small mammals. - Oecologia 103: 241-248.

O'Connell, M. A. 1986. Population variability of Neotropical rodents: influence of body size, habitat, and food habits. Rev. Chil. Hist. Nat. 59: 169-178.

Pearson, O. P. 1975. An outbreak of mice in the coastal desert of Peru. - Mammalia 39: 375-386.

Péfaur, J. E., Yáñez, J. L. and Jaksic, F. M. 1979. Biological and environmental aspects of a mouse outbreak in the semi-arid region of Chile. - Mammalia 43: 313-322.

Philippi, F. 1879. A plague of rats. - Nature 20: 530.

Rodriguez, J. E. 1993. Roedores plaga: un problema permanente en América Latina y el Caribe. - FAO, Oficina Regional para América Latina y el Caribe, Santiago, Chile.

Saunders, G. R. and Giles, J. R. 1977. A relationship between plagues of house mice, Mus musculus (Rodentia: Muridae) and prolonged periods of dry weather in south-eastern Australia. - Aust. Wildl. Res. 4: 241-248.

Stenseth, N. C. and Ims, R. A. 1993. The biology of lemmings. - Academic Press.

Torres-Contreras, H. et al. 1997. Spatiotemporal variability of rodent subpopulations at a semiarid Neotropical locality. - J. Mammal. 78: 505-513.

Trexler, J. C. and Travis, J. 1993. Nontraditional regression analyses. - Ecology 74: 1629-1637. 
This document is a scanned copy of a printed document. No warranty is given about the accuracy of the copy. Users should refer to the original published version of the material. 